\title{
ON THE REBOUND: HOW CAN WE MEET OUR CARBON TARGETS IN LIGHT OF REBOUND EFFECTS?
}

\author{
Y. Hübner $\uparrow$, P.T. Blythe $\uparrow$ \\ † Newcastle University, UK \\ School of Civil Engineering and Geosciences, Cassie Building, NE1 7RU, p.t.blythe@ newcastle.ac.uk
}

Keywords: Sustainable transport, energy, $\mathrm{CO}_{2}$ emissions, policy

\begin{abstract}
Purpose of this paper is to estimate the rebound effects of innovative traffic management and public transport systems. This paper reviews what rebound effects are and how they apply to transport for technologies such as fuel efficient vehicles, telecommuting, e-commerce and fuel prices. We will identify innovations and best practice for sustainable transport strategies around the world, and make a wide ranging set of recommendations on how we can meet our carbon targets without falling short because of rebound effects.
\end{abstract}

\section{Introduction}

Transport now accounts for about $20 \%$ of global manmade carbon dioxide emissions and $24 \%$ of emissions in the United Kingdom. The UK Government has committed itself in the Climate Change Bill to an $80 \%$ reduction of green house gas emissions by 2050. This includes all sectors, and requires urgent and substantial progress in the promotion of sustainable transport.

According to UK energy sector indicators 2009 , the total industrial energy consumption has fallen by $51 \%$ since 1970 [1]. However, transport has been the biggest single energy user in the UK in the past 21 years, accounting for $38 \%$ of final energy 
use in 2008. While the energy consumption of industry has decreased steadily over the years, the energy consumption of transport has increased and is now the largest user of energy.

Transport however not only underpins our daily lives, but is often referred to as the prerequisite for economic growth. The Eddington Transport Study [2] highlighted that transport systems have played a pivotal role for economic growth in many economies. The performance of such transport systems can boast or hinder growth of gross domestic product (GDP).

A number of policies have been implemented with the aim to reduce the carbon emissions from transport. However, research has shown that there are unintended consequences from some of the measures taken. This paper explores the impact of policies and technical innovations on the carbon footprint energy consumption.

This paper summarises the findings of a report on the rebound effects and unintended consequences from transport policy and transport innovation, which was prepared by the IET's Transport Policy Panel. The research was undertaken following a breakfast policy meeting between the IET Policy Panel and members of the Transport Select Committee, where members of the Select Committee who expressed an interest learning more about examples of transport policy that did not necessarily achieve the desired result for one reason or another, what was coined at the meeting as 'the rebound effect'.

\section{Definition of rebound effects}

\subsection{Rebound effects}

The world has become more and more complex and decisions have far reaching consequences which sometimes cannot be foreseen when an assessment is originally made. Every action may create one or more effects, some of which will be unforeseen or unintended, sometimes called rebound effects.

Rebound effects are the difference between the engineering estimate and the real energy savings after implementing new technologies and policies due to unforeseen or unrelated activities. This feedback-effect can be defined as the part of the initially expected energy savings that is lost because of the energy-economy-environment interaction. As a result, the engineering approach tends to over-estimate the net-benefits from improvements in energy efficiency [3].

The idea of rebound effects was first related to energy efficiencies by Khazzoom [4] and Brookes [5] and is often referred to as the Khazzoom-Brookes postulate [6]. It states that "with fixed real energy prices, energy efficiency gains will increase energy 
consumption above what it would be without these gains." In other words, improved energy efficiency will lead to higher overall energy consumption. Economists usually distinguish between a direct and indirect rebound effect.

\subsection{Direct rebound effects}

The direct rebound effect can be broken down into the

- Output effect: Energy efficiency improvements during the manufacture of a commodity reduce the cost of production. It is therefore possible to produce more of a product when keeping the energy use constant. This increase in supply leads to a decrease in price and should stimulate demand. As a consequence all inputs (i.e. materials, water, labour, energy) are increased $[7,8]$.

- Substitution effect: If the energy price drops, then manufacturers can use the cheaper energy service to substitute for capital, labour and other materials whilst maintaining a constant production level.

- Income effect: Energy improvements for the consumer mean that they increase their real income, which allows them to increase consumption of goods and services.

\subsection{Indirect rebound effects}

The indirect rebound effect can be broken down into the

- Secondary fuel use effect results from increases in demand for other goods and services. Consumers will not increase their consumption of a service indefinitely. Constraints on their time, changes in fashion or boredom limit the use of any one commodity and they use the saved money for other services and goods. Consumers for example may use the cost savings from energy efficiency improvements in their car to purchase other goods and services which themselves require energy to provide. Cost savings that are made during the every-day commute may for example be put towards an overseas holiday.

- Embodied energy: The equipment used to improve energy efficiency requires energy to manufacture and install. Electric vehicles for example may be more fuel efficient, but the manufacture of batteries in itself is energy-intensive. This embodied energy consumption will offset some of the energy savings achieved.

- Transformational effect: Innovations such as cars, refrigerators and mobile phones have lead to intrinsic changes in the societal behaviour $[8,9]$.

\section{Rebound effects of different policies and transport innovations}




\subsection{Fuel efficient vehicles}

The rebound effect for road transport manifests itself in either an increase in the number of vehicles, an increase in fuel consumption through increased use of other technical innovations and/or an increase in vehicle miles travelled. The easiest way to measure the rebound effect is from the vehicle-miles travelled (VMT). It costs less to drive one mile when vehicles are more energy efficient. If there is no rebound effect, then the VMT should remain constant. The rebound effect is the VMT increases after fuel efficiency improvements have been made. A number of studies have estimated the rebound effect from fuel efficiency improvements in cars.

UKERC reviewed 17 studies on the long-run direct rebound effect of fuel efficiency improvements and come to the conclusion that it lies between $10 \%$ and $30 \%$ [8]. Studies that did not include vehicle age as an explanatory variable tend to give higher estimates of the rebound effect. Walls et al. for example demonstrated that rebound effects could be $29 \%$ for single-vehicle households, $41 \%$ for two-vehicle households and 78\% for three-and-more vehicle households [10] and Puller and Greening estimated the rebound effect to be $49 \%$. When vehicle age is included in the estimates of the rebound effect, then they are between $10 \%$ and $30 \%$ [11].

Throne-Holst argued that it is not sufficient to focus on price mechanisms. Some of the energy efficiency improvements in vehicle technology are absorbed by innovations that lead to a more comfortable driving experience and safety features. Those devices increase the weight and direct energy use of cars on the market [9].

Ruzzenenti and Basosi found that in light and heavy duty trucks the power increased and the fuel economy decreased between 1978 and 2005. They believed that if efficiency is pursued in times of low energy prices, then the energy enhancements are likely to be converted into power increases. In the ideal case energy losses in form of heat are reduced and thus lead to an increase in energy efficiency [12].

Finally, the European Environment Agency concludes that although the energy efficiency of passenger and freight road transport has been improved, gains have been far outpaced by increasing transport demand [13].

\subsection{Fuel prices}

The Congressional Budget Office (CBO) reviewed in their 2008 study the effects of petrol prices on driving behaviour and vehicle markets [14]. Between 2003 and 2007 the average retail price for one gallon of petrol in the United States almost 
doubled. A $10 \%$ increase in the retail price of petrol lead to a reduced consumption of about $0.6 \%$ in the short run. Those changes are likely to come from changes in behaviour such as

- Driving more slowly: The $\mathrm{CBO}$ report shows that a 50 cents increase in fuel prices lead to a reduction of the average speeds on uncongested urban freeways by nearly 0.75 miles per hour.

- Accelerating more slowly and breaking more smoothly

- Undertaking fewer journeys

- Switching to alternative modes of transport: The CBO report showed that where a modal shift from road traffic to rail was possible, the average traffic on freeways declined by about $0.7 \%$.

- Car pooling

- $\quad$ Driving in easier traffic conditions

A $10 \%$ sustained increase in fuel prices can lead to a reduction in fuel consumption of about $4 \%$ in the long-run. Responses in the long-run include short-term behavioural changes in addition to measures like:

- Buying more fuel efficient vehicles: The share of light trucks on the U.S. market declined from about $55 \%$ in 2004 to $52 \%$ in 2006.

- Moving closer to the workplace

Those findings were mirrored in a study by the Department for Transport [15]. They found that an increase of fuel prices by $10 \%$, resulted in a decrease in traffic volume of about $1 \%$ within one year, building up to a reduction of about $3 \%$ in the longer run. Furthermore, the fuel consumption was reduced by $2.5 \%$ within one year, and $6 \%$ in the longer run. The total number of vehicles was found to go down by less than $1 \%$ in the short run and $2.5 \%$ in the longer run.

\subsection{Price elasticity - How much are drivers prepared to pay for petrol}

Price elasticity of demand reflects the quantity demanded of a good or service depending on the price. The demand for a product is inelastic if consumers will pay almost any price for the product. Demand for a product is elastic if consumers will only pay a certain price, or a narrow range of prices, for the product. The short-run price elasticity is a measure of the change in driving behaviour as a result of change in petrol prices. Those responses include a reduction in the amount people drive and eco-driving. Drivers for example tend to accelerate slower and drive at reduced speed. 
Small and Van Dender estimated that the short-run elasticities of miles driven and fuel consumption with respect to fuel price declined over the past decades [16]. Those results were echoed by Hughes et al. who found that the short-run price elasticity of U.S. petrol demand is significantly more inelastic between 2001 and 2006 than it was between 1975 and 1980 [17].

Reasons for this decrease in the short-run elasticity might include:

- Land-use: Increases in suburban developments have led to larger distances between travel destinations. This means that people are more dependent on cars as their daily transport means and cannot easily change to other modes of transport such as walking, cycling or public transport.

- Increased income: As incomes rise, a greater number of trips are discretionary which might make them also less sensitive to price increases. People on lower incomes reduce their travel to a minimum and have little room to change their behaviour in light of high petrol prices.

- Fuel efficiency: Since the vehicle fleet has become more fuel efficient, a decrease in distance travelled leads to a lower reduction in fuel consumption than in the 1980s.

\subsection{Travel time budget and travel time use}

Lyons and Urry summarise personal travel across Great Britain. They illustrate that between 1952 and 1999 the distance travelled increased from 218 billion passenger kilometres to 728 billion passenger kilometres. Between 1972 and 2000 the average annual distance travelled per person increased by $53 \%$, while the average number of trips increased only by $8 \%$ and the time spent making these trips increased only by $2 \%$. They argue that this has been achieved by increasing journey speeds. Those figures have given rise to the idea of a constant travel time budget [18]. Schafer summarised this notion by claiming that people spend about the same time travelling per day. If transport becomes faster, people travel further [19].

The theory about time budgets is however much disputed. Höjer and Mattsson for example warn that this idea is too simplistic [20]. They caution that there is a danger of generalising. Londoners for example spend $30 \%$ more time travelling than those living in Scotland. Mokhtarian and Salomon argue that people try to actively decrease travel time if it exceeds their desired optimum, but seek to increase travel time if it falls short of their ideal amount. This is because travel time is not necessarily viewed as negative [21]. 
Mokhtarian and Salomon note that travel time is often perceived as 'anti-activity time' which helps commuters to relax, reflect on the day or to mentally shift from work to leisure or vice versa. They also stress that people take pleasure from their journey such as enjoying the sensation of speed or marvelling at scenic routes. All those factors encourage longer travel times [21]

The Travel time budget hypothesis however is widely disputed. Kitamura et al. [22] for example summarised two studies by Fujii et al. which studied the effect of a 10 min reduction in commuting time. The model indicated that as a result commuters spent about 1.88 min longer on out-of-home activities and $7.11 \mathrm{~min}$ more on in-home activities. The average travel time increased by only $0.36 \min [23]$.

\subsection{Telecommuting}

Working from home is often quoted as one way to reduce the environmental impact. Telecommuting has been found to reduce the overall vehicle use by $50-70 \%$ [24]. It allows the reduction of company office space and cuts down on the daily commute, which also has got a positive impact on congestion. It does however require energy to heat or cool the home office. It may also lead to people moving further from the workplace, which could stretch urban cities further apart (this is often referred to as sprawl). Aebischer and Huser reported that there would be a $30 \%$ increase in household energy use if one person in a household was working from home [25]. It was also found that the number of non-commuting trips increases slightly with telecommuting [26].

Mokhtarian estimated that $1-2 \%$ of vehicle travel could be reduced by telecommuting, and that long-term benefits might be even smaller because of urban sprawl [27]. In 2000 Mokhtarian reported that when taking all rebound effects into account, a net reduction in vehicle miles travelled might be as low as $0.6 \%$ or even less [28]. Matthews and Williams found that for current estimated telecommuting populations and practices in the United States and Japan result in only $0.01-0.4 \%$ national energy savings in the United States and 0.03-0.36\% national energy savings in Japan. Even if 50\% of information workers adopted telecommuting, 4 days per week, the potential energy savings are estimated to be only about 1\% [24]. Roth et al. estimated that 4 million telecommuters in the U.S. who work from home one or more days per week reduce the primary energy consumption by about $0.13-0.18 \%$ and the net $\mathrm{CO}_{2}$ emissions by $0.16 \%-0.23 \%$ [29]. Reduced travel accounted for most of the reduction in the calculation and reduced floor space also made a large contribution. In addition to that, about $0.8 \%$ of lightduty vehicle fuel consumption could be saved. However, the group warns that early adopters tend to have longer than average commutes, which might reduce the effect of telecommuting if it was used more. On the other hand, companies might be able to further reduce their floor space, which would make telecommuting more beneficial. 
Rebound effects from telecommuting can include:

- Urban sprawl: employees who use telecommuting may move further from their workplace because they commute on fewer days

- Additional trips: telecommuters often have to make additional trips for shopping or to run errands which they would have otherwise done during the commute

- Change in vehicle use: the vehicle might be used by other household members when it would have otherwise been used for the commute

- Additional heating: Telecommuters often use energy to heat or cool their homes and to power electronic equipment

- Extended network of friends: People might use the telecommunications equipment to stay in touch more with friends and family in further parts of the country. This then could lead to further travel when those people want to meet up.

\subsection{E-commerce}

E-commerce is an area where ICT could have a significant impact on the environmental footprint by optimising transport logistics, reducing overproduction and warehouse space. Just-in-time delivery was found to reduce the material inventory by 28\% [30]. Downey reported that U.S. companies were able to significantly cut logistics expenditure by introducing ICT in their purchasing system [31]. Other studies however show that those savings depend on parameters such as load rate of vehicles, delivery distance and population density. Online-shopping also changes the structure of delivering freight towards smaller units, which increases packaging.

It was also demonstrated that environmental savings can be achieved if online shopping replaces 3.5 traditional shopping trips, if 25 orders are delivered at the same time or if travel distance is longer than $50 \mathrm{~km}$ [32]. Matthew and Hendrickson demonstrated that roughly the same amount of energy is used to distribute 1 million dollars worth of bestseller books in U.S. metropolitan areas by traditional retails (28-33 TJ of energy) as by online shopping (30 TJ of energy) [33]. A similar study in Japan concluded that traditional retail has a lower environmental impact in dense urban areas [34]

\section{Picking winners}

Transport is an essential part of our life. Yet, a large part of our transport needs is generated due to the design of our living spaces. People travel to get to work, bring children to school, to shop and to visit family and friends. Not only have that, but goods and food had to travel long distances to the shops. 
The previous chapters have shown how assumptions one could make about the $\mathrm{CO}_{2}$ impact or energy consumption can be wrong. It is therefore an important role for ITS (Intelligent Transport Systems) to help gain a detailed understanding of how decisions relate to energy use and $\mathrm{CO}_{2}$ emissions.

ITS can be used to increase the understanding of travel patterns. Smart ticketing allows accurate estimates of travel times, interchanges, and end-to-end journeys. It can therefore be used to improve existing transport links for certain routes and times, which will make public transport more attractive to passengers.

Intelligent transport systems such as eCall have helped to reduce the need for travel and optimise emergency responses. It automatically calls the emergency services and transmits location data from the scene of road accidents. This reduces the response time and emergency services are being automatically given information about the type of accident that occurred and the necessary response package. This reduces the need for several vehicles to come to the accident site to asses what the correct response is and for a number of vehicles arriving unnecessarily.

Active motorway management can be used to reduce peak-time congestion, can help reduce the $\mathrm{CO}_{2}$ emissions and fuel consumption, whilst easing congestion on these routes. This is one example how ITS can be used to manage the existing road network more effectively.

There is a need for more innovative approaches. If villages are too small to make local amenities viable, then those amenities can be brought to the consumer. A case to case analysis has to be made and not premature conclusions should be reached. There is a way to do this more sustainably. Delivery routes can then again be optimised using ITS.

In order to overcome rebound effects, the need for travel needs to be reduced. Cities must provide job opportunities, housing, education, amenities and recreational facilities. In order to reduce the need for transport, those services should ideally be close together and connected through public transport links. By reducing the need to travel, a large number of rebound effects can be avoided. So called "compact" or "polycentric" cities mean that average journey distances, trip frequencies, traffic volumes, energy consumption and/or transport emissions can be reduces. However, in reality the situation is much more complex. The Victoria Transport Policy Institute estimated that local land use factors (neighbourhood density, mix, design, etc.) can reduce 
per capita vehicle travel 10-20\%, while regional land use factors (location of development relative to urban areas) can reduce automobile travel 20-40\% compared with overall national average values [35].

\section{Opportunities for new unintended consequences in the era of 'doing more with less'}

In 2010 the UK is faced with a period of austerity not seen since the end of the Second World War, as the Government attempts to reduce the unprecedented national debt. Departments, such as the DfT (Department for Transport) and BIS (Business, Innovation and Skills) will face budget reductions in the region of $25-40 \%$, leading to the challenge of how we do 'more for less'. On the face of it, such reductions in budget seem daunting, however they also raise clear opportunities for the ITS community, as it is very likely technology will play an increasing role in delivering more for less, through optimisation and the automation of systems and through the clear opportunity to use ITS as a 'glue' to join up services and departments which are complimentary or even overlapping in roles but currently operating in silo's [36]. A classic problem with many local authorities, where, for example, transport, health, IT and the environment departments operate independently rather than exploiting synergies to deliver more integrated policy-thinking and service delivery. However, there is the issue that many of the local authorities have no technology champions, little technical expertise to evaluate technology options or enough revenue to implement new technologies [37].

There is a danger, that if budgets are cut too far, there will be too little resource to deliver an adequate transport network and that existing infrastructure is not maintained or refreshed, leading to additional costs to the economy at a later time. The growth in GDP and traffic are proven to follow the same trajectory. The Eddington Transport Study estimated that eliminating existing congestion on the road network would be worth some $£ 7-8$ billion of GDP per annum and concluded that if road congestion was left unchecked, the rising cost of congestion will waste an extra $£ 22$ billion worth of time in England alone by 2025 .

Particularly in times of austerity, following best procurement practices, which include the running and maintenance costs as well as the acquisition costs, is important. Procurement rules need to be designed to be fair, transparent and cost effective.

\section{Conclusion and recommendations}

This paper debates the unintended consequences of transport innovation and transport policy. The good news first: technological advances help to reduce the $\mathrm{CO}_{2}$ emissions from transport. Fuel efficient vehicle, telecommuting, electric vehicles and other technologies will all play a role in moving countries closer to achieving their carbon reduction targets. 
However, technologies and policy measures often lead to rebound effects and unintended consequences. Those policies do not render policies ineffective, but reduce their benefits. It is therefore important to quantify the rebound effects of those policies in order to account for them when devising roadmaps to meet carbon reduction targets. Below are seven recommendations for policy makers:

1. Climate change is a real threat to our planet and policy makers have to take bold decisions to reduce the $\mathrm{CO}_{2}$ emissions and energy use from transport. Those reductions will have to be implemented through a mix of behavioural changes and technical innovations.

2. Most decisions result in some unintended consequences or lead to rebound effects. Studies have shown that there are benefits to new technologies. In order to maximise the benefits, the implementation of those technologies has to be reviewed on a case to case basis. Policy makers have to be careful not to generalise. E-commerce for example has got great benefits in some scenarios and little to none in others.

3. Policy makers must not get overwhelmed by their task and use the rebound effect as an excuse to do nothing. Research has shown that unintended consequences do not result in an increase in $\mathrm{CO}_{2}$ emissions or energy use. There is a cost attached to doing nothing (as impressively demonstrated by the Stern review) and is not an option.

4. Whole life cycle analysis has to be performed. Policy makers have to be careful that emissions are not simply moved from one sector to another. Countries also have to account for the emissions from the manufacturing of goods - even if those have been produced abroad. The climate will change whether $\mathrm{CO}_{2}$ was emitted in Europe or Asia.

5. Policy makers have to account for rebound effects when implementing $\mathrm{CO}_{2}$ emission targets.

6. Carbon pricing needs to be considered as a means to mitigate the indirect rebound effect. The devil lies in the detail and a fair system needs to be devised which accommodates for people on low incomes, areas with little or no public transport, minority groups and other issues. 
7. Research is needed in greater detail about rebound effects. The more accurate our knowledge is on the unintended consequences, the better we can account for them. It will also allow policy makes to pick scenarios that minimise rebound effects. This is particularly important for large-scale projects such as high speed rail or electrifying road transport.

\section{Acknowledgements}

The authors would like to thank the members of the IET Transport Policy Panel for lively discussions and their invaluable help in preparing this paper. We also acknowledge our appreciation of a number of Members of Parliament who provided comment and input to the research and the policy recommendations outlined in this paper.

\section{References}

[1] Department of Energy \& Climate Change: UK Energy Sector Indicators, 2009

[2] Eddington, R: The Eddington Transport Study, 2006

[3] Musters, A.P.A.: The energy-economy-environment interaction and the rebound effect (Netherlands Energy Research Foundation ECN, Petten, The Netherlands, 1995)

[4] Khazzoom, J.D.: Economic Implications of Mandated Efficiency in Standards for Household Appliances, Energy J., 1980, 1, (4), pp 21-40

[5] Brookes, L.. The greenhouse effect: The fallacies in the energy efficiency solution, Energy Policy, 1990, 18, (2), pp 199201

[6] Saunders, H.D.: The Khazzoom-Brookes postulate and neoclassical growth, Energy Journal, 1992, 13, (4), p 131

[7] Greening, L.A., Greene D.L., and Difiglio, C.: Energy efficiency and consumption - the rebound effect - a survey; Energy Policy, 2000, 28, pp 389-401

[8] UK Energy Research Centre (UKERC): The rebound effect: an assessment of the evidence for economy-wide energy savings from improved energy efficiency, 2007 
[9] Throne-Holst, H.: The Fallacies of Energy Efficiency: The Rebound Effect?, Strategies for sustainable energy technology workshop, Trondheim, Norway, 2003

[10] Walls, M.A., and Krupnich, A.J.: Estimating the demand for vehicle-miles travelled using household survey data: results from the 1990 Nationwide Personal Transportation Survey, Energy and Natural Resources for the Future, Washington, DC 1993

[11] Puller, S.L., and Greening, L.A.: A decomposition of the household adjustment to gasoline price change. International Energy Markets: Competition and Policy. Proceedings of the 18th Annual North American Conference of the International Association of Energy Economists, San Francisco, USA, 1997

[12] Ruzzenenti, F., and Basosi, R.: The role of the power/efficiency misconception in the rebound effect's size debate: Does efficiency actually lead to a power enhancement?, Energy Policy, 2008, 36, pp 3626-3632

[13] European Environment Agency: Transport at a crossroads - TERM 2008: indictors tracking transport and environment in the European Union, 2009

[14] Congress of the United States Congressional Budget Office (CBO): Effects of Gasoline Prices on Driving Behaviour and Vehicle Markets., Publication No. 2883, 2008

[15] Department for Transport: Review of Income and Price Elasticities in the Demand for Road Traffic, 2002

[16] Small, K., and Van Dender, K.: Fuel efficiency and motor vehicle travel: the declining rebound effect; Energy J., 2007, 28, (1), pp 25-51

[17] Hughes, J.E., Knittel, C.R., and Sperling, D.: Evidence of a shift in the short-run price elasticity of gasoline demand; Energy J., 2008, 29, (1), pp 93-114

[18] Lyons G., and Urry, J.: Travel time use in the information age, Transport. Res. A-Pol., 2005, 39, pp 257-276 
[19] Schafer, A.: The global demand for motorized mobility, Transport. Res. A-Pol, 1998, 32, (6), pp 455-477

[20] Höjer, M., and Mattsson, L.-G.: Determinism and backcasting in future studies; Futures, 2000, 32, pp 613-634

[21] Mokhtarian, P.L., and Salomon, I.: How derived is the demand for travel? Some conceptual and measurement considerations, Transport. Res. A-Pol., 2001, 35, pp 695-719

[22] Kitamura, R., Fujii, S., and Pas, E.I.: Time-use data, analysis and modelling: toward the next generation of transportation planning methodologies, Transport Policy, 1997, 4, (4), pp 225-2325

[23] Fujii, S., Kitamura, R., and Monma, T.: A study of commuters' activity patterns for the estimation of induces trips, Journal of Infrastructure Planning and Management (Japan Society of Civil Engineers), 562, (IV-35), pp 109-203, as quoted by [22]

[24] Matthews, H.S., and Williams, E.: Telework Adoption and Energy Use in Building and Transport Sectors in the United States and Japan. J. Infr. Syst.,2005, 21, pp 21-30

[25] Aebischr, B., and Huser, A.: Networking in private households: impacts on electricity consumption, Bern, Switzerland: Swiss Federal Office of Energy, Electricity Research Programme, 2000

[26] Mokhtarian, P.L.: A synthetic approach to estimating the impacts of telecommuting on travel. Urban stud., 1998, 35, (2), pp $215-241$

[27] Mokhtarian, P.L.: Now that travel can be virtual, will congestion virtually disappear?, Scientific American, 1997, October Issue, 93

[28] Mokhtarian, P.L.: Modeling employees' perceptions and proportional preferences of work locations: the regular workplace and telecommuting alternatives, Transport. Res. A-Pol., 2000, 34, (4), pp 223-242 
[29] Roth, K..W., Rhodes, T., and Ponoum, R., The energy and greenhouse gas emission impacts of telecommuting in the U.S., IEEE Int. Symp. on Electronic and the Environment, 2008

[30] Romm, J., Rosenfield, A., and Hermann, S.: The internet economy and global warming, 1999, as quoted in [32]

[31] Downey, M.: Workshop on implications of the new digital economy on transport: developing research and data needs, National Academy of Sciences, 2000

[32] Plepys, A.: The grey side of ICT, Environ. Impact Asses, 2002, 22, pp 509-523

[33] Matthews, H.S., and Hendrickson, C.: Economic and environmental implications of online retailing in the United States, (2001) as quoted by [32]

[34] Williams, E., and Tagami, T.: Energy analysis of e-commerce and conventional retail distribution of books in Japan, 1999, as quoted by [32]

[35] Victoria Transport Policy Institute. Online TDM Encyclopedia.

[36] Blythe, P.T.: Doing more for less with ITS: Opportunities in an age of austerity. Proc. TRL Academy Symposium, London, 2011, July

[37] IET and ITS UK: Can we really do more at less cost with the UK road network? Factfile prepared by the Institution of Engineering and Technology and The Intelligent Transport Society of the UK, 2011. Available to download from http://www.theiet.org/factfiles/transport/more-for-less-page.cfm 